\title{
INTEGRATED SOLID WASTE MANAGEMENT: A CASE STUDY OF A HOTEL IN KATHMANDU, NEPAL
}

\author{
Suja Giri \\ Environment Education and Sustainable Development, Kathmandu University, Lalitpur, Nepal
}

Article DOI: https://doi.org/10.36713/epra7024

DOI No: 10.36713/epra7024

\begin{abstract}
The amount of solid waste is rapidly increasing due to urbanization. Kathmandu, the capital city of Nepal is facing the bigger challenges day by day which are usually caused by rapid urbanization and modernization of the city. Cities around the world are playing an ever-increasing role in creating wealth, enhancing social development, attracting investment and harnessing both human and technical resources for achieving unprecedented gains in productivity and competitiveness. This study explored the solid waste management practices of a hotel in Kathmandu. I used ethnographic research design in doing this study. The discussion was done with hotel staffs, waste management company staffs and an expert of the solid waste management field. Hotel has been highly benefitted from the integrated solid waste management system. There is proper system and record of waste generated, recyclables recovered and the amount of waste transferred to the landfill site.
\end{abstract}

KEYWORDS: Solid waste, hotel waste, green hotel, Nepal

\section{INTRODUCTION}

Solid waste has become a burning problem of this contemporary world. The amount of solid waste is rapidly increasing due to urbanization (Khanal \& Giri, 2016). The waste stream of our households consists of over $66 \%$ biodegradable component (ADB, 2013). If the source of waste generation does not make any effort, then all wastes are either disposed or incinerated leading to land wastage, air, water and land pollution, wastage of materials and energy, growth of unwanted animals, plants and microorganism etc (Agarwal, 2010). The solid waste can be sustainably managed in local level through the contribution and participation by the local people. For this reason, modern waste management strategy puts emphasis on the waste handling at the source of generation, so that reduce, reuse and recycling (3Rs) principle can be applied in various levels for material recovery and waste minimization.

The sustainable management of solid waste has become a strategic issue in most of the developing countries due to low budget and poor administrative practices (Ouda, Raza, Nizami \& Rehan, 2016). Worldwide, increasing population density along with population migration from rural to urban areas and industrial expansion lead to great amounts of waste generation resulting in socio-economic and environmental issues (Vitorino, Gonzalez, Faceli \& Casadei, 2017).
An efficient way to manage the solid waste is to produce energy and value-added products from waste (Rehan et al., 2016). The recycling could be categorized as the most positively received type of solid waste management practice and as an essential part of solid waste management (Renbi \& Sutanto, 2002). In developed countries, solid waste is often viewed as an asset of recyclable materials, energy, and revenue, if wisely managed (Rehan et al., 2016).

Integrated solid waste management (ISWM) is a comprehensive waste prevention, recycling, composting, and disposal program focusing on how to prevent, recycle, and manage solid waste in ways that most effectively protect human health and the environment (Sridevi, Modi, Chandana \& Kesavarao, 2012). ISWM involves a series of complementary actions to reduce and recover value from wastes, and to dispose in an environmentally sound manner of those wastes that for technical and economic reasons cannot be eliminated or recovered (SWANA, 2003). It is seen that the final disposal of wastes at sanitary landfills is given the lowest priority in an Integrated Waste Management approach.

Solid waste generation and disposal is one of the most negative impacts of hotels on the environment (Zorpas, Lasaridi,Voukkali, Loizia \& Inglezakis, 2012). If the hotels make an attempt on managing their waste themselves, they will benefit economically as well as fulfill their environmental responsibility (Cingoski \& 
Petrevska, 2017). Waste reduction and recycling are coming to be recognized as the basic premises of all waste management (WEDC, 1990).

Waste reduction provides a number of long-term benefits to tourism facilities and their host communities such as cost savings, greater operational efficiency, environmental protection, improved image and customer satisfaction (Ezeahu, Fazakerley \& Byrne, 2010). The mindset of the employees needs to be changed through conscious effort and constant training to make them understand the value of their contribution towards sustainability (Dongre \& Joshi, 2012). It is essential to educate and train staff about waste minimization practices, along with providing incentives to enhance their commitment to the programme (Radwan, Jones \& Minoli, 2009). If the organic wastes and dry wastes can be segregated properly, the value from the wastes can be obtained easily.

The hidden costs of waste include unnecessary time spent on waste handling, storage, and clean-up as well as the expense of disposing of materials that are not used and have to be written off as waste. These costs can represent a significant drain on a hotel's resources. Sometimes focusing on waste can lead to unexpected savings in other areas (Sustainability Victoria, 2006).

The tourism industry currently faces increasing demands from consumers to achieve levels of environmental responsiveness. Thus, companies strive to implement environmentally friendly and socially responsible practices to gain competitive advantage, while still maintaining commercial success (Anuwichanont, Mechinda, Serirat \& Popaijit, 2011). Though the room, parking, open space and even sewerage canal are properly built, it is difficult to find a hotel that even looks after the proper management of solid wastes within its premises.

\section{RELEVANT LITERATURES}

Hotel generates large amount of food wastes, followed by dry wastes and hazardous waste. It is known that of all the different types of waste, food waste is one of the most important materials to divert from landfills due to the fact that it decomposes to create methane, a potent greenhouse gas which significantly contributes to climate change (Pirani \& Arafat, 2014). Not much literature is available on waste management in the hospitality industry. For example, a 2012 review of environment-related research articles published in major hospitality journals accounted for only 58 articles in the period from 2000 to 2010 (Myung, McClaren \& Li, 2012). Most of the literatures explain the food waste to be of huge volume waste produced from the hotels.

A study done in 120 different hotels of Vietnam found that the waste recycling and composting potential of the hotel's SWM should be analyzed, assessed in detail and planned explicitly for deployment, aiming to minimise waste generation (Phu, Hoang \& Fujiwara, 2018). A study on SWM practice of five-star hotels in Cairo, Egypt indicated that, although these hotels sorted waste at source successfully, reduce, reuse and recycle practices were not effective (Phul, Hoang \& Fujiwaral, 2006). Another study carried out in 52 different hotels of the United Kingdom found that recycling was the most widely adopted waste management strategy, with waste prevention and reuse methods being considerably underutilized (Lazareva, 2016).

A survey conducted in 349 hotels found the two major directions that need to be followed when introducing environmental sustainability into the hotel industry. The first involves incorporating responsible technical and behavioural practices in the sector. The second highlights the necessity of initiating greater demand for "green" practices from the customers (Paulina, 2006).

A case study done in hotels of Zimbabwe and South Africa found that some hotel managers do not implement green management initiatives to mitigate the environmental problems emanating from their hotel operations (Mbasera, Plessis, Saayman \& Kruger, 2016). The subject of environmental sustainability in hotels is relevant, and it is directly related to the global concerns with the survival of the planet itself (Rosa \& Silva, 2016).

In most tourism facilities guest rooms, kitchens, restaurants, laundries, offices, gardens and conference rooms generate large volumes of solid waste which can result in negative ecological, disease and aesthetic impacts (UNEP, 2013). These wastes could be hazardous and should be managed in proper way.

A study conducted to know the practices of hotels in Vietnam regarding energy, water and SWM, 60\% of surveyed hotels were found to be selling food waste to local collectors to be used for feeding animals, 10-30\% of solid waste was separated and sold to local collectors for recycling and $10-30 \%$ of reusable items (e.g. plastic bottles and cans) were sold to local scrap collectors (Trung \& Kumar, 2005). A study conducted in Zimbabwe revealed that there is no existing legislation for environmentally-friendly initiatives to be mandatory in hotels (Mbasera, Plessis, Saayman \& Kruger, 2016).

Taiwan has a successful waste management system due to the combination of integration technologies with strong government enforcement for appropriate policies. The food waste $(\mathrm{FW})$ management model of Taiwan could probably be applied to address the FW issue in developing countries (Chang, Liu, Hung, Allen \& Chen, 2008). In 2002, Taiwan executed a program called "Total Recycling for Kitchen Garbage," which targeted segregating and collecting FW from residential areas, restaurants, and hotels. The $80 \%$ of collected FW was used for animal feeding and rest $20 \%$ for producing fertilizer (Chen \& Geng, 2008).

A study conducted in Zimbabwe revealed that there is no existing legislation for environmentally-friendly initiatives to be mandatory in hotels (Mbasera, Plessis, Saayman \& Kruger, 2016). Government regulations, consumer demands, professional ethics, and the initiatives of professional associations, international organizations, and non-governmental organizations are the key forces in the hotel industry worldwide (Erdogan \& Baris, 2017).

The hidden cost of waste includes unnecessary time spent on waste handling, storage, and clean-up, as well as the expense of disposing of materials that are not used and 
have to be written off as waste. These costs can represent a significant drain on a hotel's resources. Sometimes focusing on waste can lead to unexpected savings in other areas (Sustainability Victoria, 2006). If the wastes are properly managed at source, the storage and transportation time and cost are reduced.

The hotel industry is undergoing a quite transformation. An increasing number of hotels are demonstrating that by taking a few simple steps, they can save money and resources by reducing their waste while also making a positive difference for the environment. In addition, more and more travelers expect that the places they stay are environmentally conscious, and are favoring hotels that demonstrate this awareness in their everyday practices. One of the simplest and most effective ways that hotels can lessen their environmental impact is to reduce the amount of waste that they produce (Sustainability Victoria, 2006). Since tourism activities are linked to the characteristics of the setting, businesses in the tourism industry (such as hotels) depend on the sustainability of a high-quality environment and therefore, have a role to play in the enhancement of natural and cultural resources (WTTC, 1996). Hotels often generate large quantities of solid waste, in the form of packaging materials, kitchen and garden waste, old furniture and equipment, and potentially hazardous waste such as asbestos and solvents.

\section{RESEARCH QUESTIONS}

Below were the research questions for this study.

1. How is the solid waste management practices adopted by Hotel Namaste?

2. How do hotel management people find the level of difficulty in ISWM?

3. How do hotel management people find ISWM in practice?

\section{METHODOLOGY}

My study has incorporated a vivid dimension of waste management aligned to the Ontology query such as, "how they are and what they do (Shrestha, 2015)." I have used a case study for carrying out this study which is often described as qualitative inquiry (Creswell, 2014). I have used purposive sampling method to choose a hotel as I wanted to select a unique case that is especially informative (Ishak \& Bakar, 2014). I studied hotel Namaste (pseudo name) that has been practicing ISWM in Nepal. For gathering information, I had interviews with the staffs from kitchen and stewarding and housekeeping as well. The interviews were also carried out with the waste management company, working staffs and waste buying vendor. Along with this, the perception of waste management expert was also drawn to capture the overall scenario of waste management in Nepal.

\section{DISCUSSION}

Earlier the waste was collected by private vendors on daily basis. All the wastes generated from hotel were collected in bins in different departments of hotel. Then the bins were bought to the cold room for storage of waste material. So, from there the waste was directly loaded in the truck. The segregation was done in the truck itself and rest of the material were transferred to landfill site directly for dumping. Hotel had no exact data of how much waste was generated, recycled and dumped. Hotel simply paid monthly for their waste disposal to the earlier vendors. This was the scenario of the waste management of the hotel Namaste around two years ago.

Currently a private company has been involved in the process of waste management system of the hotel which is practicing integrated solid waste management system within the premises of hotel. They have been practicing waste segregating at the source in every departments of the hotel. For this, they have separate bins in blue and green color. Blue bin is for dry waste and green bin is for wet waste. The collected waste is carried to the material recovery facility (MRF) for further processing. Wet wastes that are edible or that comes from kitchen are sold as a feed for animal farm where other remaining wet waste are processed by machine and made into compost that is sold in the market. The remaining dry wastes are further segregated into different categories and stored separately for selling to different vendors. Lately, they have also been practicing for the processing of rejected waste for its recovery. In this process, they have tried recycling tetra pack and thermacol. However, during my observation and discussion with the food collector, I came to know the source segregation is not fully practiced by the hotel. Integrated solid waste management (ISWM) has been introduced to streamline all the stages of waste management viz. source separation, collection and transportation, transfer stations and material recovery, treatment and resource recovery and final disposal (Memon, 2010). During the study, I found that there is no proper source segregation of the waste. The waste collection by the vendor is also not satisfactory as food leftover is properly ensured taking out recyclables before transportation. There is no full treatment of all the wastes collected.

The hotel confirms that the waste segregation gets mixed during the big events and program. The hotel has limited staffs and all are busy in other works. The bin placement and waste storage portion are not properly handled by staffs during the rush period. According to the Integrated Sustainable Waste Management framework' structured by Van de Klundert, member of the Dutch NGO WASTE, stakeholder is one major dimension of ISWM (Garcia, 2017). It includes the waste workers roles and responsibility for effective solid waste management. The voice representation is a also major part of integrating waste workers into the channel. The company which is managing the waste of the hotel should not shadow this issue.

The hotel management and the waste collection company both face several difficulties with the ISWM practice at the hotel. The major challenge faced by the hotel is the late pick up of the collected waste. If the waste remains unpicked for longer day the environment of the hotel is affected. It gives the poor hygiene remarks and gives negative influence to guests. 
Landfill often remains closed time to time due to conflict with locals at Okharpauwa i.e. where landfill is located this becomes the major challenge for the company that manages waste. Compared to previous scenario the waste that goes to landfill is much lesser in quantity even though piling the waste and storing it for many days does create problem. The other difficulty seen is that, when there are big event in the hotel it is tough for hotel staff to follow segregation in rush hours so they throw the waste randomly which further makes difficulty in final segregation. The other issue they often faced is to search the staff for waste segregation department. As it is a tough job and is not considered as white color job it is difficult to get a staff for this section. The other challenge they frequently face is the interference from earlier vendors. They come to waste company time to time and disturb them in their functioning.

Hotel highly benefits from the integrated solid waste management system being followed because it gives positive message towards guest as they are fulfilling their environmental responsibility by less polluting their surroundings. The systematic management of waste helps them record the total waste generated, recovered and sent to landfill. From this, the hotel can minimize their loss on excessive wastage that can be controlled. Main problems associated with waste management in most developing countries are low waste collection rates, low recycling levels (recycling limited to informal recyclers) littering, and inappropriate final disposal. Due to the implementation of ISWM at this hotel, there are positive changes experienced by the hotel management. The waste collection and disposal frequency is comparatively higher than earlier waste collectors. Apart from that, the company has been able to obtain maximum recyclables by segregation of waste at its MRF.

\section{CONCLUSION}

My three research questions were about the practices of waste management at Hotel Namaste, views of hotel management regarding the implementation of ISWM and difficulties faced in the implementation of ISWM at the hotel.

From the study, I came to know that the current waste management system of the hotel has changed since the implementation of integrated model of solid waste management. The waste collection frequency has increased as the waste workers have been deployed at the site for regular waste collection.

There was no proper source segregation of waste mainly in the kitchen areas. Though there are different roles and responsibilities assigned to both the parties (hotel and company). I found the lack of proper coordination between Hotel Namaste and Jagaran Nepal. Due to this, the impact has been seen over the food waste collecting vendors. The vendors need to re-segregate the food waste to remove recyclables before transferring it to the farm.

The hotel confirms that the waste segregation gets mixed with them during the big events and program. The hotel has limited staffs and all are busy in other works so there is less time for proper segregation. The bin placement and waste storage portion are not properly handled by staffs during the rush period. Apart from that the landfill obstruction has also caused problem to the company. One of the main challenges of ISWM is coordinating the stakeholders and getting them to work together for a common goal (Anschutz, 2004). Due to the lack of coordination between hotel, company and related stakeholders, there is problem in the implementation of ISWM in the hotel.

The waste segregation at the source is not satisfactory. The waste transportation to the MRF is also time consuming. Though the recovery of items is better, still the manual process of re-segregating waste is time consuming. Apart from this, the hazardous waste are not properly treated and transferred to the landfill site. Thus, the hotel fails to implement the fullest ISWM system.

\section{Acknowledgements}

I would like to express my sincere gratitude and deep appreciation to the faculty members of Kathmandu University School of Education for their outstanding supportive guidance and valuable feedback throughout my research. I am much grateful to Asst. Professor Mr. Parbat Dhungana and lecturer Mr. Basu Prasad Subedi for their valuable inputs and ideas during the study.

\section{REFERENCES}

1. $A D B$ (2013). Solid Waste Management in Nepal: Current Status and Policy Recommendations. Asian development Bank. Retrieved from https://www.adb.org/sites/default/files/publication/3036 6/solid-waste-management-nepal.pdf

2. Agarwal, R. (2010). Waste management initiatives in India for human well being. Retrieved from http://home.iitk.ac.in/ anubha/H16.pdf

3. Anuwichanont, J., Mechinda, P., Serirat, S. \& Popaijit, N. (2011). Environmental sustainability in the Thai hotel industry. International Business and Economics Research Journal, 10(11).

4. Chang, Y.M., Liu, C.C., Hung, C.Y., Allen, H. \& Chen, S.S. (2008). Change in MSW characteristics under recent management strategies in Taiwan. Waste Management, 28(12), 2443-2455.

5. Chen, W.C. \& Geng, D.S. (2008. The strategy and bioenergy potential for kitchen waste recycling in Taiwan. Environment Engineering Management, 18(4), 281-287.

6. Cingoski, V. \& Petrevska, B. (2016). Making hotels more energy efficient: The managerial perception. Economic Research-Ekonomska Istraživanja, 31(1)

7. Creswell, J. W. (2014). Research design: Qualitative, quantitative and mixed methods approaches. Sage Publication.

8. Dongre, R. \& Joshi, S. (2012). Study of recyclable waste generated in Pune star hotels with reference to guest rooms. Atithya: A Journal of Hospitality, 1(2)

9. Erdogan, N. \& Baris E. (2007). Environmental protection programs and conservation practices of hotels in Ankara, Turkey. Tourism Management, 28(2), 604-614.

10. Garcia, A.M.L. (2017). A technological approach towards integrated solid waste management in 
developing countries. Jyväskylä University School of Business and Economics. Retrieved from https://jyx.jyu.fi/bitstream/handle/123456789/54649/1/U RN\%3ANBN\%3Afi\%3Ajyu-201706223024.pdf

11. Khanal, A. \& Giri, S. (2016). Possibility of community based solid waste management project in Chuchepati, Kathmandu. Journal of Basic and Applied Engineering Research, 2(12), 32-33.

12. Lazareva, Y. (2016). Exploring the differences in waste management strategies in different types of hotels. Surrey Undergraduate Research Journal (SURJ), 2(1)

13. Mbasera, M., Plessis,E.D., Saayman, M. \& Kruger, M. (2016). Environmentally-friendly practices in hotels. Independent Research Journal in the Management Sciences, 16(1)

14. Memon, M.A. (2010). Integrated solid waste management based on the $3 R$ approach. Journal of Material Cycles and Waste Management, 12(1), 30-40.

15. Myung, E., McClaren, A. \& Li, L. (2012). Environmentally related research in scholarly hospitality journals: Current status and future opportunities. International Journal of Hospitality Management, 31(4), 1264-1275.

16. Ouda, O., Raza, S.A., Nizami, A.S. \& Rehan, M. (2016). Waste to energy potential: A case study of Saudi Arabia. Retrieved from https://econpapers.repec.org/article/eeerensus/v_3a61_3 ay_3a2016_3ai_3ac_3ap_3a328-340.htm

17. Paulina, B. (2006). Environmental awareness and initiatives in the Polish and Swedish hotel industries. Survey results. International Journal of Hospitality Management, 25(4), 662-682.

18. Phul, P., Hoang, M.G. \& Fujiwaral, T. (2006). Analyzing solid waste management practices for the hotel industry. Global Journal of Environmental Science and Management, 4(1), 19-30.

19. Pirani, S. \& Arafat, H.A. (2014). Solid waste management in the hospitality industry: A review. Journal of Environmental Management. 21(146), 320 336.

20. Radwan,H., Jones,E. \& Minoli,D. (2009). Managing solid waste in small hotels. Journal of Suatainable Tourism, 18(2)

21. Rehan, M., Nizami, A.S., Shahzad, K, Ouda, O., Ismail, I., Almeelbi, T., Iqbal, $T$ \& Demirbas, A. (2016). Pyrolytic liquid fuel: A source of renewable electricity generation in Makkah

22. Renbi, B. \& Sutanto, M. (2002). The practice and challenges of solid waste management in Singapore. Waste Management, 22(5), 501-506.

23. Sridevi, V., Modi, M., Chandana, M.V.V. \& Kesavarao, L. (2012). A review on integrated solid waste management. International Journal of Engineering Science \& Advanced Technology, 2(5),1491-1499.

24. Sustainability Victoria, (2006). Waste wise hotel. Retrieved from http://www.sustainability.vic.gov.au//media/SV/Publications/About-Us/What-wedo/Corporate-reporting/Annual-reporting/AnnualReport-SV-2006-07-Book-Two.pdf

25. Trung, D.N. \& Kumar, S. (2005). Resource use and waste management in Vietnam hotel industry. Journal of Cleaner Production, 13(2005),109-116.

26. United Nation Environment Programme (2004). Developing integrated solid waste management plan. Retrieved from http://www.unep.or.jp/ietc/Publications/spc/ISWMPlan_ Vol4.pdf
27. Vitorino, A., Gonzalez, S,M., Faceli, K., \& Casadei, V. (2017). Technologies and decision support systems to aid solid waste management: A systematic review. Waste Management, 59(8), 567-584.

28. WEDC. (1990). Women and solid wastes in developing countries. Hyderabad, India

29. World Trade Organization (1996) Agenda 21 for the travel \& tourism industry - Towards environmentally sustainable development. London, UK.

30. Zorpas, A.A., Lasaridi, K., Voukkali, I., Loizia, P. and Inglezakis, V.J. (2012). Solid waste from the hospitality industry in Cyprus. Island Sustainability II, 9(166), 4149. 